Ciência Florestal, Santa Maria, v. 27, n. 1, p. 181-191, jan.-mar., 2017

ISSN 1980-5098

\title{
TROCAS GASOSAS E GRAU DE TOLERÂNCIA AO ESTRESSE HÍDRICO INDUZIDO EM PLANTAS JOVENS DE Tabebuia aurea (PARATUDO) SUBMETIDAS A ALAGAMENTO
}

\author{
GAS EXCHANGE AND TOLERANCE DEEGREE IN YOUNG PLANTS OF Tabebuia aurea \\ 'PARATUDO', UNDER FLOODING
}

\author{
${\text { Ademir Kleber Morbeck de Oliveira }{ }^{1} \text { Sônia Cristina Juliano Gualtieri² }}^{2}$
}

\begin{abstract}
RESUMO
O paratudo, Tabebuia aurea, é uma árvore típica do Pantanal de Miranda, Mato Grosso do Sul, Brasil, sendo esse local, uma área de inundação sazonal. Para avaliar as trocas gasosas de Tabebuia aurea sob estresse hídrico por alagamento, grupos de plantas com oito meses de idade foram mantidas em vasos com o solo coberto por uma lâmina de 2 a $3 \mathrm{~cm}$ de água. As taxas de condutância estomática, transpiração e fotossíntese foram determinadas durante o período de experimento (115 dias), através de um analisador portátil de gás infravermelho. Os valores de condutância estomática no início do experimento estavam em torno de 0,22 mol m$~^{-2} \mathrm{~s}^{-1} \mathrm{e}$ foram decrescendo até $0,02 \mathrm{~mol} \mathrm{~m}^{-2} \mathrm{~s}^{-1}$. Em relação à fotossíntese líquida, o valor máximo inicial foi de $8,0 \mu \mathrm{mol} \mathrm{m} \mathrm{m}^{-2} \mathrm{~s}^{-1}$, atingindo zero no $108^{\circ}$ dia. Após redução em $100 \%$ da fotossíntese líquida, as plantas foram retiradas da condição de alagamento e avaliadas ( 8 dias). Os valores obtidos ao final do processo de recuperação para condutância estomática foram: $0,21 \mathrm{~mol} \mathrm{~m}^{-2} \mathrm{~s}^{-1} \mathrm{e}$ fotossíntese $=8,0 \mu \mathrm{mol} \mathrm{m}^{-2}$ $\mathrm{s}^{-1}$. O alagamento do solo reduziu a fotossíntese, a condutância estomática e afetou o crescimento da parte aérea, induzindo o aparecimento de sintomas característicos de estresse por inundação, como a hipertrofia das lenticelas. Porém, a espécie apresenta tolerância ao estresse, indicando adaptabilidade a áreas sujeitas a alagamento periódico.
\end{abstract}

Palavras-chave: fotossíntese; estresse por inundação; condutância estomática; tolerância a hipóxia.

\begin{abstract}
'Paratudo', Tabebuia aurea, is a common Brazilian tree from 'Pantanal de Miranda', Mato Grosso do Sul state, Brazil, an area with seasonal floodplain. To evaluate the gas exchange of Tabebuia aurea under flooding stress, groups of eight-month-old plants were grown in soil covered by a 2 to $3 \mathrm{~cm}$ layer of water and a control group. Stomatal conductance, transpiration and photosynthetic rates were measured during the experiment (115 days), with an infrared portable analyzer. The values of stomatal conductance of the control group and stress plants at the beginning of the experiment were $0.22 \mathrm{~mol} \mathrm{~m}^{-2} \mathrm{~s}^{-1}$ and reached 0.02 $\mathrm{mol} \mathrm{m} \mathrm{m}^{-2} \mathrm{~s}^{-1}$ at the end of this event. The initial photosynthesis rate was $8.0 \mu \mathrm{mol} \mathrm{m} \mathrm{m}^{-2} \mathrm{~s}^{-1}$ and, by the $108^{\text {th }}$ day, it had reached zero. When the photosynthesis rate reached zero, the rigid plastic container was dried and the rate analyzed ( 8 days). The values obtained for plants in drained soil were: stomatal conductance $=0.21 \mathrm{~mol}$ $\mathrm{m}^{-2} \mathrm{~s}^{-1}$ and photosynthesis rate $=8.0 \mu \mathrm{mol} \mathrm{m} \mathrm{m}^{-2} \mathrm{~s}^{-1}$, indicating a recovery response, returning to initial values. Flooded soil reduced photosynthesis and stomatal conductance, and it affected the shoot growth, leading to the symptoms resulting from flooding stress, such as hypertrophy of the lenticels. However, the species has a tolerance to the flooding process, indicating adaptability to areas under seasonal water stress.
\end{abstract}

Keywords: photosynthesis; flooding stress; stomatal conductance; tolerance hypoxia.

1 Biólogo, Dr., Professor do Programa de Pós-Graduação em Meio Ambiente e Desenvolvimento Regional, Universidade Anhanguera-Uniderp, Rua Alexandre Herculano, 1400, Bairro Jardim Veraneio, CEP 79037-280, Campo Grande (MS), Brasil.akmorbeckoliveira@gmail.com

2 Bióloga, Dra ., Professora do Programa de Pós-Graduação de Ecologia e Recursos Naturais, Universidade Federal de São Carlos, Rod. Washington Luiz Km 235, CEP 13565-905, São Carlos (SP), Brasil. soniacristina3012@hotmail.com

Recebido para publicação em 17/12/2013 e aceito em 28/05/2015

Ci. Fl., v. 27, n. 1, jan.-mar., 2017 


\section{INTRODUÇÃO}

O estudo comportamental de espécies arbóreas, em condições de estresse hipóxico no ambiente edáfico é de fundamental importância quando se trata de preservação ou recuperação de formações ripárias, sujeitas à inundação sazonal, pois o grau de tolerância varia de acordo com as espécies, bem como com a idade da planta e a intensidade do estresse. Por exemplo, algumas espécies tolerantes conseguem sobreviver em condições de alagamento durante a fase de crescimento, enquanto outras, mais sensíveis, morrem logo no início do período de anaerobiose edáfica (GIBBS; GREENWAY, 2003; PAROLIN, 2009; PAROLIN; WITTMANN, 2010; PAREEK et al., 2010; TAIZ; ZEIGER, 2010).

A saturação hídrica do solo provoca, de imediato, uma rápida diminuição nos níveis de $\mathrm{O}_{2}$ disponíveis devido a problemas na difusão do oxigênio na água, que é baixa, sendo que também a aeração deficiente das raízes causa um decréscimo da absorção de água pelas plantas. Em condições normais, este tipo de fenômeno ocorre com frequência em áreas sujeitas a inundações periódicas, como é o caso do Pantanal Mato-Grossense. Neste ambiente, o solo passa parte do ano com uma atmosfera oxidante e subitamente, através do processo de alagamento, os espaços anteriormente ocupados pelo ar são preenchidos com água. Em poucas horas, o oxigênio disponível para o processo respiratório desaparece e o sistema radicular da vegetação passa para um ambiente hipóxico ou anóxico (SCREMIN-DIAS ET AL., 2011).

Os efeitos do alagamento do solo, durante determinados períodos, têm sido estudados por diferentes pesquisadores, levando-se em consideração as alterações morfológicas, anatômicas, bioquímicas e fisiológicas das plantas e/ou as alterações nas trocas gasosas, como por exemplo, em trabalhos de Bockelmann et al. (2002), Voesenek et al. (2004), Mommer et al., (2004), Ezin et al., (2010), Scremin-Dias, Lorenz-Lemke e Oliveira (2011), Kato e Okami (2011), Parlanti et al. (2011), entre outros. As espécies sensíveis ao estresse desenvolvem sintomas, os quais resultam principalmente dos distúrbios causados pela hipoxia ou anoxia nas raízes, sendo os mais comuns o aumento da resistência estomática, a redução da fotossíntese, alterações nas taxas de transpiração, inibição de crescimento, murcha e/ou abscisão de folhas, entre outros (PEZESHKI, 1994; KOZLOWSKI, 1997; GIBBS; GREENWAY, 2003; PAROLIN, 2009; PAROLIN; WITTMANN, 2010; PAREEK et al., 2010).

A inundação de uma área é, geralmente, uma mudança drástica, impondo aos organismos presentes um estresse cuja intensidade e duração não são previsíveis. A flora das áreas frequentemente inundadas sofre uma forte pressão de seleção, que leva à evolução de mecanismos que permitem a sua sobrevivência nestas condições. As espécies mais adaptadas evitam a hipoxia desenvolvendo mecanismos que incluem plasticidade fisiológica, metabólica e morfológica (GIBBS; GREENWAY, 2003; PAREEK et al., 2010; SCREMIN-DIAS et al., 2011).

O Pantanal, uma planície de inundação, possui diferentes formações vegetais compostas quase que exclusivamente por uma espécie (consorciação) dominando vastas extensões como resultado de fatores edáficos e/ou hidrológicos. Como exemplos dessas formações, podem-se citar o cambarazal, com a predominância da espécie arbórea cambará (Vochysia divergens Pohl); pateiral, formado pela espécie arbórea pateiro (Couepia uiti (Mart. \& Zucc.) Benth. ex Hook.f.) e o paratudal, que tem como espécie arbórea dominante o paratudo (Tabebuia aurea (Silva Manso) Benth. \& Hook.f ex. S. Moore, família Bignoniaceae) (POTT et al., 2011), uma formação savânica alagável (Savana Parque, Savana Arbórea ou Parque de Cerrado), citada por vários autores (SOARES; OLIVEIRA, 2009; POTT et al., 2011, entre outros), mas que permanece ainda pouco estudada em sua capacidade de suportar o estresse hídrico periódico.

Levando-se em consideração o desenvolvimento da espécie Tabebuia aurea em áreas sujeitas à inundação periódica, o objetivo deste trabalho foi avaliar suas trocas gasosas sob estresse hídrico induzido por alagamento.

\section{MATERIAL E MÉTODOS}

Os frutos de Tabebuia aurea foram colhidos de 30 árvores localizadas na sub-bacia do Rio Miranda (Bacia do Alto Paraguai), no Pantanal de Miranda, Município de Corumbá, Mato Grosso do Sul, na região conhecida como Passo do Lontra (19³4’37” S; 5700’42” W). 
As sementes contidas nos frutos secos e com deiscência natural foram coletadas e triadas manualmente com a finalidade de separar aquelas em melhor estado de conservação. Em seguida foram colocadas para germinar em placas de Petri forradas internamente com uma folha de papel-filtro umedecido com solução do fungicida Captan $(0,2 \%)$ e mantidas sobre bancadas de laboratório sob temperatura de ambiente.

Após germinação, as plântulas foram colocadas em bandejas de alumínio contendo vermiculita e irrigadas diariamente com água destilada. Quando atingiram a altura de $7 \mathrm{~cm}$ acima do solo, foram transplantadas para sacos de plantio (sacos plásticos pretos para mudas, com capacidade para $7 \mathrm{~kg}$ ) já contendo o substrato. Esse substrato foi classificado como Latossolo Vermelho-Amarelo, de textura francoarenosa (MO: 2,07\%; pH: 4,33 $\mathrm{CaCl}_{2}$; P: Resina $02 \mu \mathrm{g} / \mathrm{cm}^{3}$; K: 0,09 emg/100 cm ; Ca: 0,72 emg/100 $\mathrm{cm}^{3}$; Mg: 0,56 emg/100 cm ; Al: $0,35 \mathrm{emg} / 100 \mathrm{~cm}^{3}$ ), de acordo com análises realizadas no Laboratório de Análise Química de Solo e Planta, Departamento de Recursos Naturais, Centro de Ciências Agrárias UFSCar, Campus Araras.

Para ser utilizado, o mesmo foi peneirado, colocado sobre lonas plásticas e seco a céu aberto. Cada saco recebeu uma única plântula, mantidas em casas de vegetação com temperaturas médias, máximas e mínimas de $20^{\circ} \mathrm{C}, 25 \pm 2^{\circ} \mathrm{C}$ e $15 \pm 2^{\circ} \mathrm{C}$, respectivamente, umidade relativa de $60 \pm 10 \%$ e $65 \%$ de luminosidade incidente.

A partir de 8 meses após a emergência, levando-se em consideração a disponibilidade de espaço na casa de vegetação, 15 mudas foram submetidas a estresse hídrico simulado pela inundação do solo, sendo que as mesmas foram colocadas em baldes plásticos com água, formando uma lâmina d'água variável entre dois e três $\mathrm{cm}$ acima do solo e plásticos escuros cobrindo a lâmina d'água para evitar o crescimento de algas. As plantas-controle e sob alagamento, com altura média inicial de $31 \mathrm{~cm}$ e número médio de 14 folhas, foram avaliadas em relação ao desenvolvimento em altura, crescimento de novas folhas e outros caracteres morfológicos aparentes, como hipertrofia das lenticelas.

Para a medição das trocas gasosas, três indivíduos de cada grupo (15 plantas-controle e 15 sob estresse por inundação), escolhidos aleatoriamente dentro do grupo, eram utilizados diariamente para a mensuração dos parâmetros, obtendo-se um valor médio através de um analisador portátil de $\mathrm{CO}_{2}$ por

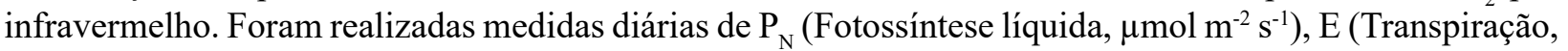
mmol m $\mathrm{m}^{-2} \mathrm{~s}^{-1}$ ) e $\mathrm{G}_{\mathrm{s}}$ (Condutância estomática em relação ao vapor d'água, mol $\mathrm{m}^{-2} \mathrm{~s}^{-1}$ ), através de três a quatro registros por folha, após a fotossíntese ter atingido valor constante, utilizando-se folíolos primários que permaneciam na câmara por um período entre 10 e 20 segundos. Também foi avaliado o potencial hídrico foliar $(\Psi \mathrm{w})$ utilizando-se uma câmara de pressão de Scholander (PMS-1000, EUA), durante o desenvolvimento do experimento.

As medidas foram realizadas em uma intensidade luminosa de $1200 \mu \mathrm{mol} \mathrm{m} \mathrm{m}^{-2} \mathrm{~s}^{-1}$ (que efetivamente alcançava a superfície foliar) obtida através de uma lâmpada de retroprojetor. Um aquário contendo água era colocado entre a fonte de luz e as plantas para evitar aquecimento excessivo das folhas. As leituras foram realizadas durante as primeiras horas da manhã, geralmente após as $7 \mathrm{~h} 30 \mathrm{~min}$, procurando-se utilizar sempre os mesmos pares de folhas para as leituras, sendo as medições realizadas durante 115 dias, com a supressão de excesso de água ocorrendo no $108^{\circ}$ dia. O experimento foi completamente ao acaso com dois tratamentos, (1) plantas sob estresse hídrico por inundação do sistema radicular e (2) plantas-controle, com irrigação diária até a saturação do solo.

Os valores médios de potencial hídrico foliar, condutância, transpiração e fotossíntese foram submetidos à análise de variância (ANOVA) e as médias comparadas pelo teste de Tukey, considerando-se um nível de significância de 5\%, através do programa estatístico Bioestat 4.0.

\section{RESULTADOS E DISCUSSÃO}

O efeito da anoxia ou hipoxia radicular foi inicialmente observado na parte aérea das plantas, que interromperam seu desenvolvimento, não crescendo em altura; ambos os grupos possuíam $31 \mathrm{~cm}$ de altura média e ao final, para plantas alagadas, não ocorreu aumento, enquanto que plantas-controle atingiram, em média, $51 \mathrm{~cm}$. Também a emissão de novas folhas foi prejudicada, sendo a média de 14 para ambos os grupos no início do experimento e ao final, 14 para plantas sob alagamento e 24 , controle. 
Estes resultados demonstram que a espécie, apesar de sobreviver ao estresse, não possui capacidade de produzir novos tecidos, que resultariam em crescimento em altura ou maior número de folhas. Segundo Martínez-Ballesta et al. (2003) e Tournaire-Roux et al. (2003), estresses abióticos como alagamento, entre outros, também afetam a condutância hidráulica dos tecidos, alterando sua resistência ao fluxo de água, além de diminuir a produção de aquaporinas, um dos subgrupos dentro da classe das Intrinsic Membrane Proteins (IMPs) responsável pelo transporte de água através de membranas. Como resultado, plantas em solos inundados possuem maior dificuldade para absorção d'água, pois este fator aumenta a resistência à absorção, ocorrendo um deficit hídrico e uma redução na turgescência celular da planta, limitando o crescimento dos tecidos (expansão foliar), além de causar uma deficiência na translocação de nutrientes do solo para o sistema radicular (SMIT et al., 1989; KOZLOWSKI, 1997).

De acordo com Vu e Yelenosky (1991) e Taiz e Zeiger (2010), o crescimento também pode ser afetado pelo acúmulo de ácido abscísico nas folhas e pela redução na produção e translocação dos fotoassimilados para os locais da maior atividade enzimática, resultado das menores taxas fotossintéticas correlacionadas, entre outros fatores, a diminuição da condutância estomática.

Normalmente, trabalhos envolvendo o crescimento de plantas sob estresse indicam que a adaptação da espécie permite seu crescimento, como relatado por Andrade et al. (1999), trabalhando com Genipa americana L. submetida à inundação durante 60 dias, indicando não ocorrer diferenças na altura da parte aérea entre plantas submetidas a estresse e controle. Batista et al. (2008), avaliando Cecropia pachystachya Trec., também indicaram que indivíduos crescendo em ambiente alagado mantiveram taxa de crescimento igual à exibida pelas plantas do grupo-controle.

Porém, o trabalho de Davanso et al. (2002) realizado com Tabebuia avellanedae Lor. ex Griseb. indicou haver um efeito negativo da inundação no crescimento das plantas sob estresse, resultado similar ao encontrado para Tabebuia aurea e trabalhos desenvolvidos por Pelecani et al., (1998a; 1998b) trabalhando com espécies florestais, tais como Eriobotrya japonica (Thunb.) Lindl., Hevea brasiliensis (Willd. ex A. Juss.) Müll. Arg., Machaerium villosum Vogel e Sesbania sesban (L.) Fawc. \& Rendle, em que as espécies estudadas não apresentaram crescimento em sua parte aérea após o início do estresse.

As folhas das plantas submetidas ao estresse não apresentaram nenhum sinal de clorose, uma reação comum em indivíduos sob anoxia/hipoxia radicular. Autores como Boru et al. (2001), trabalhando com Triticum aestivum L., Reyna et al. (2003), com Glycine max (L.) Merr. e Ezin et al., (2010), com Lycopersicon esculentum Mill., avaliando a tolerância destas espécies ao processo de inundação, encontraram clorose nas folhas em plantas inundadas, o que não foi observado para Tabebuia aurea, indicando capacidade de adaptação ao alagamento por determinados períodos.

Como alteração morfológica visual apresentada em indivíduos sob estresse, foi observada a hipertrofia das lenticelas no tronco, logo acima da lâmina d'água. Esta modificação anatômica, comum em algumas espécies de árvores quando submetidas à anoxia/hipoxia, é aparentemente induzida pelo etileno que é formado em resposta à inundação, envolvendo a dissolução de paredes celulares e proliferação de células (KOZLOWSKI, 1997). Parolin (2009) afirma que a presença de lenticelas hipertrofiadas são comumente observadas em espécies de locais com variações periódicas no nível de água. Algumas espécies, como Genipa americana, não apresentam modificações morfológicas em indivíduos submetidos à inundação (ANDRADE et al., 1999). Arruda e Calbo (2004), com carnaúba (Copernicia prunifera (Mill.) H.E. Moore) também demonstraram que as plantas não apresentaram sintomas de estresse por inundação como a clorose nas folhas, além de não desenvolverem estruturas que pudessem facilitar a aeração das raízes, como pneumatóforos, raízes adventícias ou lenticelas hipertrofiadas, indicando diferentes estratégias adaptativas.

Em relação ao potencial hídrico foliar, os valores variaram entre -0,4 e -0,6 MPa, plantas-controle e sob alagamento (Figura 1) durante todo o período de estudo, indicando que o potencial não é fortemente afetado pelo estresse por alagamento. A análise estatística também indicou que não ocorreram diferenças significativas entre os tratamentos $(\mathrm{F}=2.2014,(\mathrm{p})=0.1381)$.

De acordo com Kozlowski (1997), a manutenção do potencial hídrico foliar é derivada do fato de que, mesmo as plantas estando em solo alagado, poderia ocorrer dificuldade na absorção de água, gerando uma condição de seca fisiológica. Em trabalho com espécies da planície inundável amazônica, Waldhoff e Furch (2002) citam este tipo de comportamento, com a manutenção do potencial quando as espécies são submetidas ao processo de alagamento, com os valores encontrados para este trabalho similares aos citados 
para as plantas pertencentes ao grupo-controle da mesma espécie, Tabebuia aurea, aos cinco meses de crescimento, em trabalho desenvolvido por Oliveira, Gualtieri e Bocchese (2011).

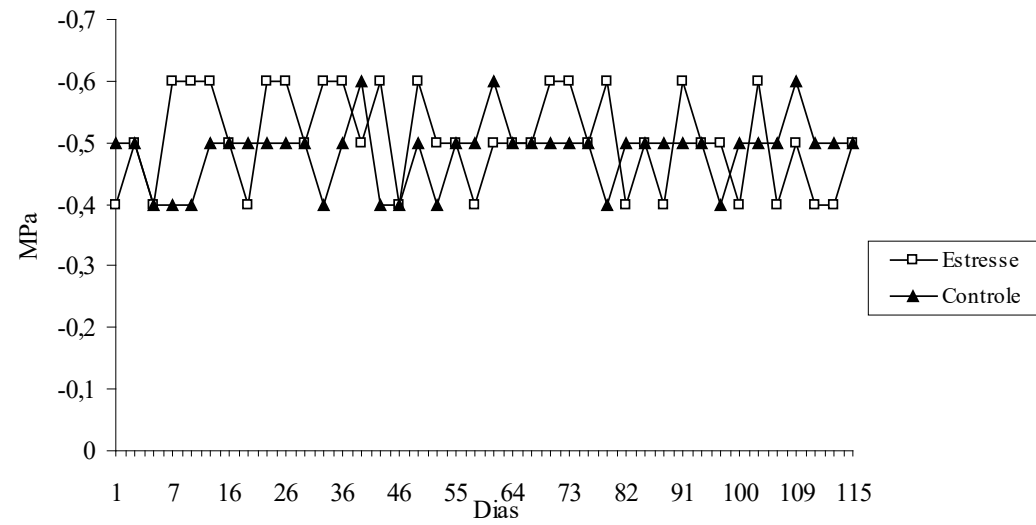

FIGURA 1: Potencial hídrico foliar (MPa) em dois grupos de plantas jovens envasadas (controle e plantas submetidas a estresse hídrico por alagamento) de Tabebuia aurea.

FIGURE 1: Leaf water potential (MPa) in two groups of young Tabebuia aurea potted plants (control and hydric stress through flooding).

O ponto de compensação luminosa (PCL) em plantas do grupo-controle, no qual a intensidade luminosa na qual a emissão de $\mathrm{CO}_{2}$ pela respiração e fotorrespiração iguala a retenção de carbono pela fotossíntese, foi de $58,5 \mu \mathrm{mol} \mathrm{m} \mathrm{m}^{-2} \mathrm{~s}^{-1}$, maior valor do que o encontrado por Calbo e Moraes (2000) com plantas de quatro meses da palmeira Euterpe oleracea Mart. $\left(18,1 \mu \mathrm{mol} \mathrm{m}^{-2} \mathrm{~s}^{-1}\right)$ e menor do que o valor citado por Rocha e Moraes (1997) com Stryphnodendron adstringens (Mart.) Coville com seis meses (59

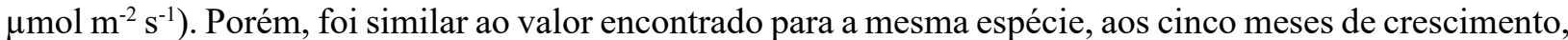
por Oliveira et al., (2011).

A taxa máxima de fotossíntese obtida para a espécie, plantas-controle, foi de $8,2 \mu \mathrm{mol} \mathrm{m}^{-2} \mathrm{~s}^{-1}$, maior dos que o encontrado por Calbo e Moraes (2000) com Euterpe oleracea $\left(4,2 \mu \mathrm{mol} \mathrm{m}^{-2} \mathrm{~s}^{-1}\right)$ e menor do que o valor citado por Rocha e Moraes (1997) com Stryphnodendron adstringens $\left(12,9 \mu \mathrm{mol} \mathrm{m}^{-2} \mathrm{~s}^{-1}\right)$. Oliveira, Gualtieri e Bocchese (2011) indicam valores similares para a mesma espécie, aos cinco meses de crescimento, para plantas pertencentes ao grupo-controle.

Franco et al. (2005) trabalhando com 11 espécies arbóreas de Savanas Neotropicais (Cerrado) encontraram valores que indicaram diferentes estratégias de comportamento, com valores oscilando ente $16,3 \mu \mathrm{mol} \mathrm{m}^{-2} \mathrm{~s}^{-1}$ (Schefflera macrocarpa (Cham. \& Schltdl.) Frodin e $8,8 \mu \mathrm{mol} \mathrm{m}{ }^{-2} \mathrm{~s}^{-1}$ (Vochysia elliptica Mart.), indicando grande diversidade de comportamento dessas espécies, em relação a fotossíntese máxima.

Para a maioria dos vegetais, a fotossíntese aumenta em resposta ao aumento da intensidade luminosa até cerca de $25 \%$ da luz solar total incidente. Quando a luz atinge intensidade de saturação, o processo fotoquímico não sofre limitação, ocorrendo, contudo, a redução da fixação de carbono através da diminuição do fornecimento de dióxido de carbono aos sítios de carboxilação; a capacidade fotossintética é uma característica intrínseca de cada espécie e as taxas mudam durante o crescimento do indivíduo, sendo muitas vezes dependente das variações dos fatores ambientais (luz, temperatura, umidade, etc.) a que as plantas estão submetidas (LARCHER, 2004; TAIZ; ZEIGER, 2010).

Plantas sob estresse atingiram, à medida que aumentava o tempo de estresse, uma taxa fotossintética menor, apesar do aumento da intensidade luminosa (Figura 2). A análise estatística indicou que as plantascontrole apresentaram resultados superiores aos demais tratamentos, enquanto que plantas sob estresse de 35 e 75 dias, possuem resultados estatisticamente iguais e sob estresse de 105 dias, as menores taxas, estatisticamente inferiores aos demais tratamentos $[\mathrm{F}=59.724,(\mathrm{p})<0.0001]$.

De acordo com Parolin (2009), Parolin e Wittmann (2010) e Pareek et al. (2010), a redução na 
condutância estomática pode diminuir a taxa de assimilação de $\mathrm{CO}_{2}$; entretanto, também o estresse por inundação pode afetar diretamente o aparato fotossintético, independentemente da condutância, devido, entre outros fatores, à redução da atividade e regeneração da ribulose 1,5-bifosfato carboxilase (rubisco), levando à diminuição da fotossíntese em plantas sob inundação.

Os resultados indicam que a espécie apresentou comportamento similar para os períodos de 35 e 70 dias de estresse, mostrando que após a redução inicial da fotossíntese, Tabebuia aurea mantém uma constância nas taxas, reduzindo apenas a fotossíntese após um período prolongado de alagamento, o que ocorreu aproximadamente aos 105 dias de tratamento. Apesar da manutenção das taxas em determinado nível, não ocorreu crescimento dos indivíduos sob alagamento, fator provavelmente relacionado ao deficit hídrico e redução na turgescência celular da planta, conforme mencionado por Smit et al., (1989) e Kozlowski (1997).

$\mathrm{O}$ comportamento dos indivíduos, em relação à condutância estomática (Figura 3), até o $10^{\circ}$ dia de tratamento, indica que as plantas inundadas e as do grupo-controle não apresentaram diferenças significativas neste parâmetro, com valores entre $0,24 \mathrm{e} 0,30 \mathrm{~mol} \mathrm{~m}^{-2} \mathrm{~s}^{-1}$. A partir do $11^{\circ}$ dia, a condutância diminuiu para $0,14 \mathrm{~mol} \mathrm{~m}^{-2} \mathrm{~s}^{-1}$ nas plantas sob estresse e permaneceu oscilando entre 0,01 e $0,17 \mathrm{~mol} \mathrm{~m}^{-2} \mathrm{~s}^{-1}$ até o $89^{\circ}$ dia. A partir deste período, houve uma diminuição de valores, permanecendo oscilando entre 0,07 e $0,09 \mathrm{~mol} \mathrm{~m}^{-2} \mathrm{~s}^{-1}$ até o $100^{\circ}$ dia. Entre o $101^{\circ}$ e $107^{\circ}$ dia, entre 0,02 e $0,03 \mathrm{~mol} \mathrm{~m}^{-2} \mathrm{~s}^{-1}$ (Figura 3), período em que as taxas fotossintéticas são as mais baixas, indicando que a redução da condutância afeta negativamente a fotossíntese, conforme citado por Kozlowski (1997). No primeiro dia após a supressão do estresse (109 ${ }^{\circ}$ dia), os valores aumentaram para $0,05 \mathrm{~mol} \mathrm{~m}^{-2} \mathrm{~s}^{-1}$, chegando $0,21 \mathrm{~mol} \mathrm{~m}^{-2} \mathrm{~s}^{-1}$ no $115^{\circ}$ dia, sendo que também as taxas fotossintéticas se elevaram acompanhando a recuperação dos valores da condutância.

Nesta fase de crescimento, os indivíduos precisaram de cinco dias para retornar aos valores iniciais de condutância, demonstrando que a capacidade de recuperação da espécie, após estresse, é rápida, para este parâmetro. A análise estatística demonstrou que os resultados apresentados por ambos os tratamentos são diferentes [F=343.809, (p)<0.0001), indicando comportamento distinto para cada situação de crescimento.

De acordo Pezeshki (1994), Kozlowski (1997), Gibbs e Greenway (2003) e Pareek et al. (2010), plantas não tolerantes à anaerobiose edáfica apresentam como reação o fechamento estomático, resultante de fatores como o aumento na concentração de ácido abscísico, síntese de etileno ou desidratação foliar, enquanto que plantas adaptadas a longos períodos de inundação conseguem a manutenção de taxas constantes de condutância estomática, resultado da capacidade de desenvolver estruturas que permitam

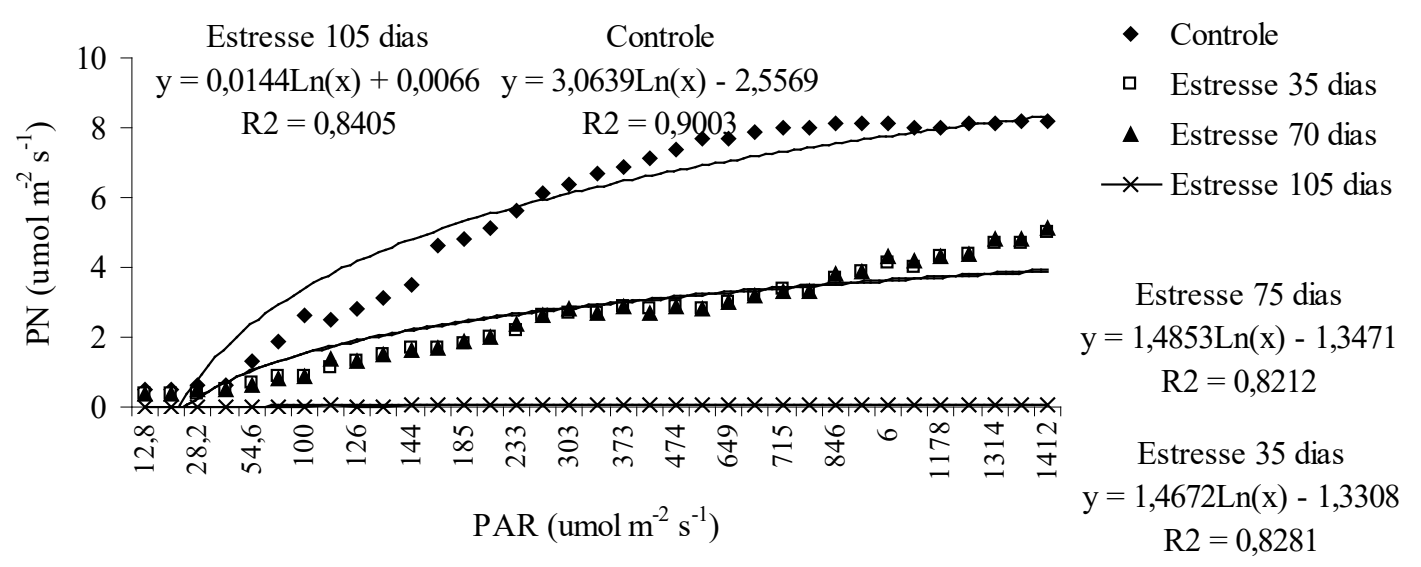

FIGURA 2: Taxa de fotossíntese líquida ( $\mathrm{PN} \mu \mathrm{mol} \mathrm{m} \mathrm{m}^{-2} \mathrm{~s}^{-1}$ ) em função da radiação fotossinteticamente ativa

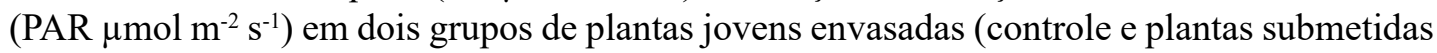
a estresse hídrico por alagamento - 35, 70 e 105 dias) de Tabebuia aurea.

FIGURE 2: Net photosynthesis rate $\left(\mathrm{PN} \mu \mathrm{mol} \mathrm{m}^{-2} \mathrm{~s}^{-1}\right)$ as a function of photosynthetically active radiation (PAR, $\mu \mathrm{mol} \mathrm{m}^{-2} \mathrm{~s}^{-1}$ ) in two groups of young Tabebuia aurea potted plants (control and hydric stress through flooding - 35, 70 and 105 days). 


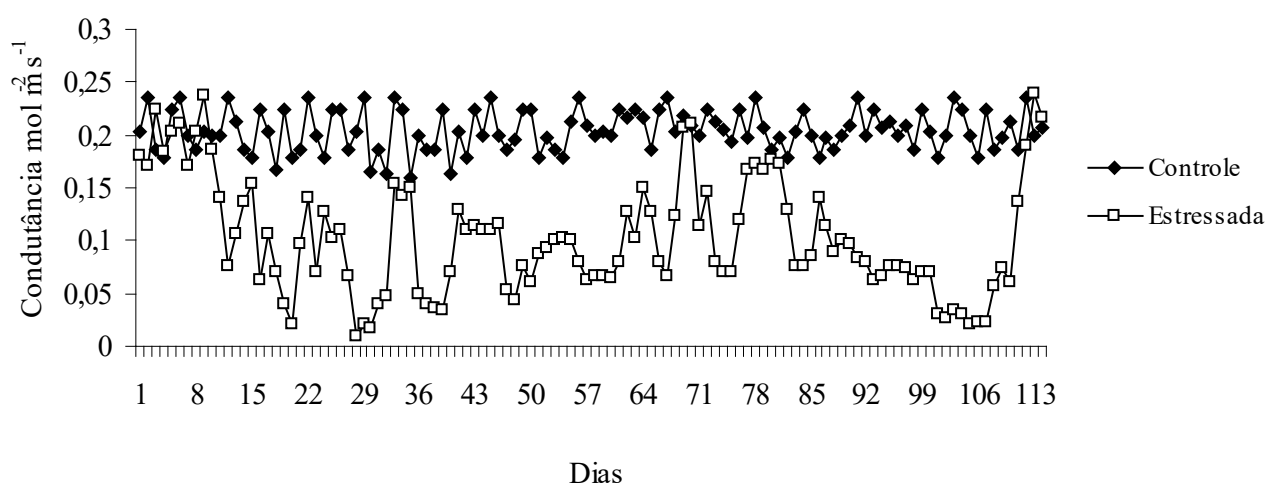

FIGURA 3: Valores médios de condutância $\left(\mathrm{mol} \mathrm{m}^{-2} \mathrm{~s}^{-1}\right)$ em dois grupos (estresse hídrico através do excesso de água e controle) de plantas jovens envasadas de Tabebuia aurea.

FIGURE 3: Conductance rates $\left(\mathrm{mol} \mathrm{m}^{-2} \mathrm{~s}^{-1}\right)$ in the two experimental groups (control and hydric stress through flooding) of young Tabebuia aurea potted plants.

a absorção de água e íons do solo, mantendo a abertura estomática, tal como a alta porosidade nas raízes.

A espécie Tabebuia aurea apresentou, em relação à condutância, um comportamento que não a enquadra claramente como planta resistente ou não ao processo de alagamento do solo, pois as taxas variaram muito no decorrer do experimento, apesar da manutenção de determinados valores durante todo o processo de inundação.

Por outro lado, espécies como Nyssa aquatica L. e Cephalantus occidentalis L., comuns em terrenos brejosos, não apresentaram diferenças na condutância estomática, quando crescidas em solos alagados (MCLEOD et al., 1987). Em plantas com menor tolerância à inundação, como Gerbera jamesonii Adlam, tal parâmetro foi significativamente reduzido em plantas inundadas com apenas seis dias de tratamento (OLIVELLA et al., 2000).

Arruda e Calbo (2004) trabalhando com Copernicia prunifera e Batista et al. (2008), com Cecropia pachystachya, encontraram redução nos valores de condutância estomática em plantas submetidas à inundação, resultado semelhante ao encontrado nesse estudo para Tabebuia aurea. No mesmo sentido, Davanso et al. (2002), com Tabebuia avellanedae, encontraram redução neste parâmetro em plantas submetidas ao estresse. Estes dados indicam que, apesar de determinadas espécies poderem suportar determinados períodos sob inundação, ocorrerá uma diminuição nas taxas, fator relacionado à própria fisiologia da espécie.

Mielke et al. (2005) obervaram aumento nos valores de condutância em plantas inundadas de Annona glabra L. a medida que aumentava o período de estresse, indicando que a sobrevivência das plântulas em ambientes sob estresse pode estar relacionada a sua capacidade de manter elevados valores de condutância estomática, fato esse não observado para Tabebuia aurea ao final do período estudado.

Avaliando-se a transpiração, foram registrados valores iniciais que oscilavam entre 1 e $2,5 \mathrm{~mol}$ $\mathrm{m}^{-2} \mathrm{~s}^{-1}$ para ambos os grupos até o $15^{\circ}$ dia, quando começam o ocorrer oscilações de valores para plantas submetidas a estresse, sem uma tendência definida, alternando períodos de baixa com alta transpiração, conforme pode ser observado na Figura 4. Mesmo quando a fotossíntese chegou a zero, as taxas de transpiração foram elevadas $\left(1,57 \mathrm{~mol} \mathrm{~m}^{-2} \mathrm{~s}^{-1}\right)$. Ao que parece, o processo de transpiração não esteve diretamente ligado à abertura dos estômatos, com as plantas perdendo água continuamente, embora autores com Parolin (2001) e Mielke et al. (2005) tenham relatado uma redução significativa da fotossíntese acompanhada pela diminuição da condutância e transpiração em espécies arbóreas tropicais tolerantes ao alagamento.

Por outro lado, exceções também foram relatadas em trabalhos de Pezeshki e Delaune (1990), com Spartina patens (Ait.) Muhl. e Pezeshki e Anderson (1997), com Taxodium distichum (L.) Rich., 


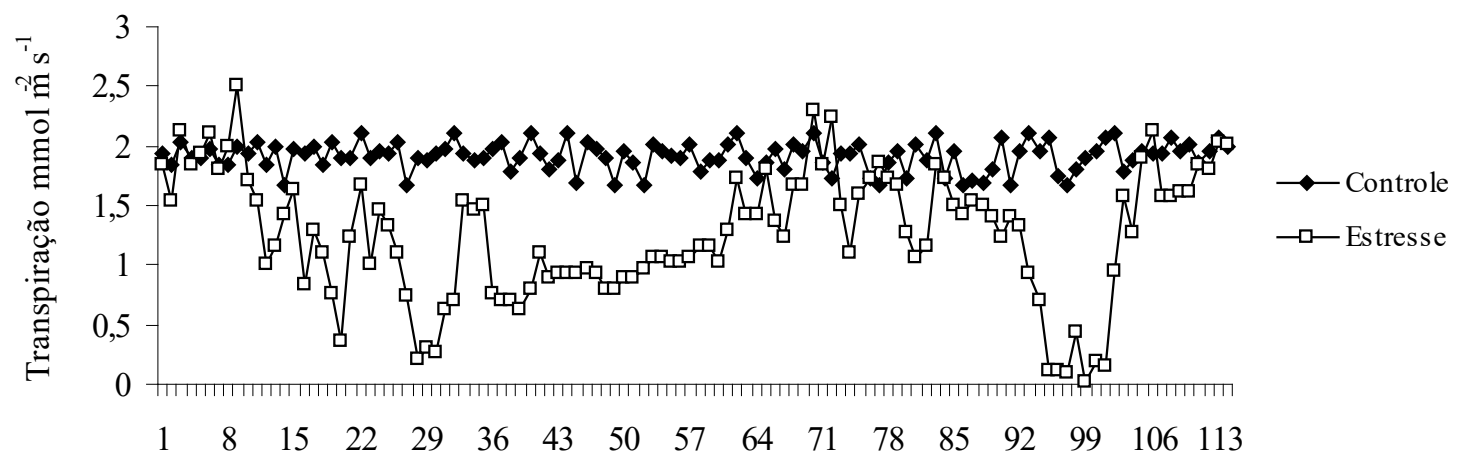

Dias

FIGURA 4: Valores médios de taxas de transpiração $\left(\mathrm{mmol} \mathrm{m}^{-2} \mathrm{~s}^{-1}\right)$ em dois grupos (estresse hídrico por alagamento e grupo-controle) de plantas jovens envasadas de Tabebuia aurea.

FIGURE 4: Transpiration rates $\left(\mathrm{mmol} \mathrm{m}^{-2} \mathrm{~s}^{-1}\right)$ in the two experimental groups (control and hydric stress through flooding) of young Tabebuia aurea potted plants.

Quercus nuttalli Palm. e Quercus falcata var. pagodaefolia Ell. Provavelmente, a sobrevivência das plantas alagadas, com a manutenção das taxas fotossintéticas por determinados períodos, está mais ligada ao desenvolvimento de lenticelas hipertrofiadas, pois não ocorreu um controle estomático acentuado levando à redução da transpiração durante o período de alagamento, com exceção de determinados dias, conforme se pode observar na Figura 4. Estas oscilações ocasionaram uma diferença estatística significante entre os dois tratamentos $[\mathrm{F}=163.5094,(\mathrm{p})<0.0001]$, demonstrando que o alagamento produziu respostas diferenciadas, com menor taxa de transpiração, em dias específicos de alagamento.

A diminuição nos valores de transpiração é esperada para as espécies qualificadas como sensíveis quando submetidas ao estresse hídrico (KOZLOWSKI, 1997; PAROLIN, 2009; PAROLIN; WITTMANN, 2010). Larcher (2004) afirma que a redução na taxa de transpiração está diretamente relacionada com o fechamento dos estômatos, resultado da redução ou deficiência total de oxigênio no solo, o que não foi observado em todos os momentos, nas plantas estressadas.

Porém, para espécies como Nyssa aquatica e Cephalantus occidentalis, não ocorrem diferenças na taxa de transpiração para plantas crescidas em solos alagados ou apenas úmidos (MCLEOD et al., 1987). Arruda e Calbo (2004), trabalhando com Copernicia prunifera, também não encontraram redução no processo de transpiração em plantas submetidas à inundação, resultado parcialmente similar ao registrado para Tabebuia aurea. Em outras espécies com menor tolerância à inundação, como Gerbera jamesonii, a taxa de transpiração foi significativamente reduzida em plantas com seis dias de inundação (OLIVELLA et al., 2000). Também Davanso et al. (2002), trabalhando com Tabebuia avellanedae, encontraram diminuição neste parâmetro em plantas sob estresse.

Em relação à fotossíntese líquida, plantas-controle e sob inundação tiveram comportamento similar até o $7^{\circ}$ dia, com valores variando entre 6,8 e $8,2 \mu \mathrm{mol} \mathrm{m}^{-2} \mathrm{~s}^{-1}$. A partir do $8^{\circ}$ até o $34^{\circ}$ dia, as plantas que permaneceram sob estresse apresentaram valores de $\mathrm{P}_{\mathrm{N}}$ com forte oscilação, entre 0,5 e $6,3 \mu \mathrm{mol} \mathrm{m} \mathrm{m}^{-2} \mathrm{~s}^{-1}$ (Figura 5). Os valores observados são estatisticamente significantes $[F=474.5078,(p)<0.0001]$, indicando que os ambientes produziram respostas diferentes, nas plantas testadas.

Davanso et al. (2002), estudando Tabebuia avellanedae, também encontraram redução na fotossíntese, em plantas inundadas, a partir do $7^{\circ}$ dia. O período entre o $35^{\circ}$ até o $99^{\circ}$ dia para Tabebuia aurea indicou pequena estabilidade, com os valores oscilando entre 2,1 e $6 \mu \mathrm{mol} \mathrm{m} \mathrm{m}^{-2} \mathrm{~s}^{-1}$, com queda acentuada no $100^{\circ}$ dia até atingir $0 \mu \mathrm{mol} \mathrm{m}^{-2} \mathrm{~s}^{-1}$ no $108^{\circ}$ dia. No $109^{\circ}$ dia, com a retirada do excesso de água, os valores das taxas começaram a aumentar, chegando a $4,2 \mu \mathrm{mol} \mathrm{m} \mathrm{m}^{-2} \mathrm{~s}^{-1} \mathrm{e}$ após oito dias, atingiram valores similares aos iniciais $\left(7,6 \mu \mathrm{mol} \mathrm{m} \mathrm{m}^{-2} \mathrm{~s}^{-1}\right)$, indicando que depois de eliminar o estresse, as taxas retornaram aos 


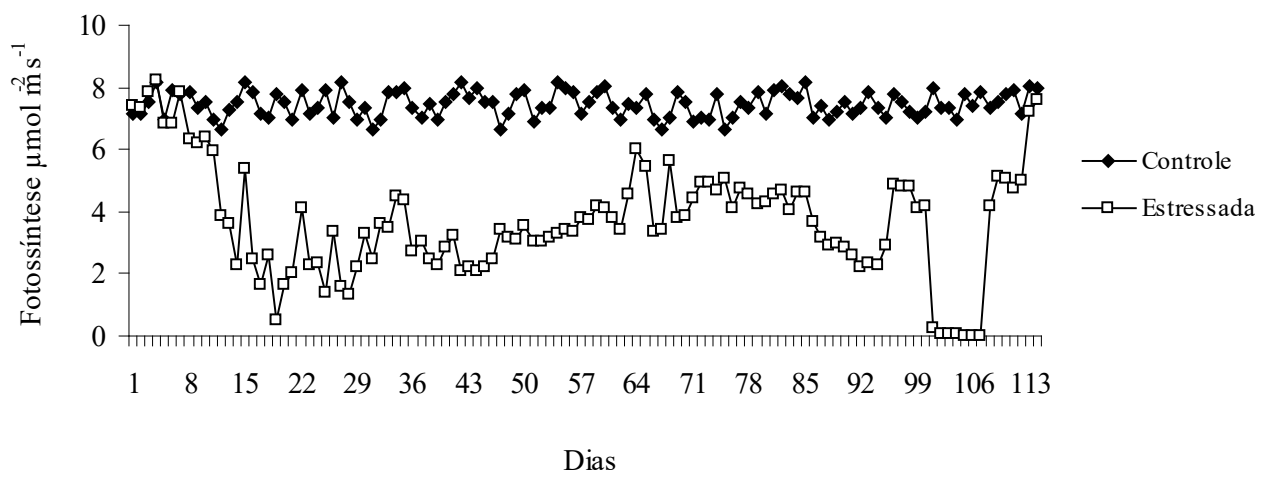

FIGURA 5: Valores médios das taxas de fotossíntese $\left(\mu \mathrm{mol} \mathrm{m}^{-2} \mathrm{~s}^{-1}\right)$ em dois grupos (estresse hídrico por excesso de água e controle) de plantas jovens envasadas de Tabebuia aurea.

FIGURE 5: Photosynthesis rates $\left(\mu \mathrm{mol} \mathrm{m} \mathrm{m}^{-2} \mathrm{~s}^{-1}\right)$ in the two experimental groups (control and hydric stress through flooding) of young Tabebuia aurea potted plants.

níveis iniciais, demonstrando também uma recuperação rápida para tal parâmetro. Analisando os registros para taxas de condutância e transpiração, pode-se observar que a taxa fotossintética flutua, em determinados momentos, em conjunto com as outras, indicando que a fotossíntese pode ser relacionada à condutância e transpiração, embora, em determinados momentos, as taxas de transpiração estejam dissociadas do processo fotossintético, como mencionado acima.

A redução na condutância estomática pode diminuir a taxa de fotossíntese, mas o estresse por inundação pode afetar diretamente o aparato fotossintético, independentemente da condutância estomática. A redução da atividade e regeneração da ribulose 1,5-bifosfato carboxilase (rubisco) e da inibição da fotossíntese por causa do acúmulo de amido (TOPA; CHEESEMAN, 1992; PEZESKI, 1994) são colocadas como prováveis causas da diminuição da fotossíntese em plantas sob inundação, além de outros fatores (PEZESHKI et al., 1993; PEZESHKI, 1994).

Davanso et al. (2002) trabalhando com Tabebuia avellanedae, Arruda e Calbo (2004), com Copernicia prunifera, Mielke et al. (2005), com Annona glabra e Batista et al. (2008), Cecropia pachystachya, verificaram redução na fotossíntese em plantas submetidas à inundação, resultado semelhante ao encontrado para Tabebuia aurea. Davanso et al. (2002) também mencionam que espécies como Tabebuia avellanedae, mesmo gênero da espécie estudada, possui a capacidade de formar novas raízes durante o processo de inundação, mais eficientes no transporte de água, oxigênio e íons, proporcionando melhores condições de sobrevivência em ambientes inundados.

\section{CONCLUSÃO}

As respostas fisiológicas apresentadas pela espécie indicam que a mesma pode sobreviver durante mais de 100 dias sob alagamento, porém, com redução das taxas fotossintéticas, de condutância e transpiração; após a retirada do estresse, a espécie possui rápida recuperação, voltando suas taxas fisiológicas aos níveis iniciais.

\section{AGRADECIMENTOS}

Ao CNPq pela bolsa concedida a ambos os autores.

\section{REFERÊNCIAS}

ANDRADE, A. C. S. et al. Flooding effects in seedlings of Cytharexyllum myrianthum Cham. and Genipa 
americana L.: responses of two neotropical lowland tree species. Revista Brasileira de Botânica, São Paulo, v. 22, n. 2, p. 281-285, 1999.

ARRUDA, G. M. T.; CALBO, M. E. R. Efeitos da inundação no crescimento, trocas gasosas e porosidade radicular da carnaúba (Copernicia prunifera (Mill.) H.E. Moore). Acta Botanica Brasilica, São Paulo, v. 18, n. 2, p. 219-224, 2004.

BATISTA, C. U. N. et al. Tolerância à inundação de Cecropia pachystachya Trec. (Cecropiaceae): aspectos ecofisiológicos e morfoanatômicos. Acta Botanica Brasilica, São Paulo, v. 22, n. 1, p.91-98, 2008.

BOCKELMANN, A. C. et al. The relation between vegetation zonation, elevation and inundation frequency in a Wadden Sea salt marsh. Aquatic Botany, Amsterdam, v. 73, n. 3, p. 211-221, 2002.

BORU, G. et al. Expression and inheritance of tolerance to waterlogging stress in wheat. Euphytica, Wageningen, v. 117, n. 2, p. 91-98, 2001.

CALBO, M. E. R.; MORAES, J. A. P. V. Efeitos da deficiência de água em plantas de Euterpe oleracea (açaí). Revista Brasileira de Botânica, São Paulo, v. 23, n. 3, p. 225-230, 2000.

DAVANSO, V. M. et al. Photosynthesis, growth and development of Tabebuia avellanedae Lor. Ex Griseb. (Bignoniaceae) in flooded soil. Brazilian Archives of Biology and Technology, Curitiba, v. 45, n. 3, p. 375-384, 2002.

EZIN, V.; DE LA PENA, R.; AHANCHEDE, A. Flooding tolerance of tomato genotypes during vegetative and reproductive stages. Brazilian Journal of Plant Physiology, Londrina, v. 22, n. 1, p. 131-142, 2010.

FRANCO, A. C. et al. Leaf functional traits of Neotropical savanna trees in relation to seasonal water deficit: from wet to dry: tropical trees in relation to water availability. Trees: Structure and Function, New York, v. 19, n. 3, p. 326-335, 2005.

GIBBS, J.; GREENWAY, H. Mechanisms of anoxia tolerance in plants. I. Growth, survival and anaerobic catabolism. Functional Plant Biology, Victoria, v. 30, n. 1, p. 1-47, 2003.

KATO, Y.; OKAMI, M. Root morphology, hydraulic conductivity and plant water relations of high-yielding rice grown under aerobic conditions. Annals of Botany, Oxford, v. 108, n. 3, p. 575-583, 2011.

KOZLOWSKI, T. T. Responses of woody plants to flooding and salinity. Tree Physiology Monograph, Victoria, v. 1, n. 1, p. 1-29, 1997.

LARCHER, W. Ecofiosiologia vegetal. São Carlos: RiMa, 2004. 531 p.

MARTÍNEZ-BALLESTA, M. C. et al. Influence of saline stress on root hydraulic conductance and PIP expression in Arabidopsis. Journal of Plant Physiology, Minneapolis, v. 160, n. 6, p. 689-697, 2003.

MCLEOD, K. W.; DONOVAN, L. A.; STUMPFF, N. J. Responses of woody seedlings to elevate flood water temperatures. In: HOOK, D. D. et al. (Eds.). The ecology and management of wetlands. Portland: Timber Press, 1987. p. 441-451.

MIELKE, M. S. et al. Some photosynthetic an growth responses of Annona glabra L. seedlings to soil flooding. Acta Botanica Brasilica, São Paulo, v. 19, n. 4, p. 905-911, 2005.

MOMMER L.; PEDERSEN, O.; VISSER, E. J. W. Acclimation of a terrestrial plant to submergence facilitates gas exchange under water. Plant, Cell and Environment, Oxford, v. 27, n. 10, p. 1281-1287, 2004.

OLIVELLA, C. et al. Hormonal and physiological responses of Gerbera jamesonii to flooding stress. HortScience, Alexandria, v. 35, n. 2, p. 222-225, 2000.

OLIVEIRA, A. K. M.; GUALTIERI, S. C. J.; BOCCHESE, R. A. Gas exchange of potted Tabebuia aurea plants under hydric stress. Acta Scientiarum. Agronomy, Londrina, v. 33, n. 4, p. 641-647, 2011.

PARLANTI, S. et al. Distinct mechanisms for aerenchyma formation in leaf sheaths of rice genotypes displaying a quiescence or escape strategy for flooding tolerance. Annals of Botany, Oxford, v. 107, n. 8, p. 1335-1343, 2011.

PAREEK, A. et al. (Eds.). Abiotic stress adaptation in plants: physiological, molecular and genomic foundation. Dordrecht: Springer, 2010. 526 p.

PAROLIN, P. Morphological and physiological adjustaments to waterlogging and drought in seedlings of Amazonian floodplain trees. Oecologia, Berlin, v. 128, n. 3, p. 326-335, 2001.

PAROLIN, P.. Submerged in darkness: adaptation to prolonged submergence by woody species of the Amazonian floodplains. Annals of Botany, Oxford, v. 103, n. 2, p. 359-376, 2009.

PAROLIN, P.; WITTMANN, F. Struggle in the flood: tree responses to flooding stress in four tropical

Ci. Fl., v. 27, n. 1, jan.-mar., 2017 
floodplain systems. AoB Plants, Oxford, p. 1-19, 2010.

PELECANI, C. R.; OLIVEIRA, L. E. M.; CRUZ, J. L. Respostas de algumas espécies florestais à baixa disponibilidade de oxigênio no meio de cultivo. I - Alterações em algumas características de crescimento. Revista Árvore, Viçosa, v. 22, n. 1, p. 61-67, 1998a.

PELECANI, C. R.; OLIVEIRA, L. E. M.; CRUZ, J. L. Respostas de espécies florestais à baixa disponibilidade de oxigênio. II - Alterações na produção e distribuição de matéria seca. Pesquisa Agropecuária Brasileira, Brasília, v. 33, n. 1, p. 37-41, 1998b.

PEZESHKI, S. R. Plant responses to flooding. In: WILKINSON, R. E. (Ed). Plant environment interactions. New York: Marcel Dekker, 1994. p. 289-321.

PEZESHKI, S. R.; ANDERSON, P. A. Responses of three bottomland woody species with different floodtolerance capabilities to various flooding regimes. Wetland Ecology and Management, Netherlands, v. 4, n. 4, p. 245-256, 1997.

PEZESHKI, S. R.; DELAUNE, R. D. Influence of sediment oxidation-reduction potential on root elongation in Spartina patens. Acta Oecologica, Amsterdam, v. 11, n. 3, p. 377-383, 1990.

PEZESHKI, S. R.; PARDUE, J. H.; DELAUNE, R. D. The influence of soil deficiency on alcohol dehydrogenase activity, root porosity, ethylene production and photosynthesis in Spartina patens.

Environmental and Experimental Botany, Amsterdam, v. 33, n. 4, p. 565-547, 1993.

POTT A. et al. Plant diversity of the Pantanal wetland. Brazilian Journal of Biology, São Carlos, v. 71, n. 1, p. 265-273, 2011.

REYNA, N. et al. Evaluation of a QTL for waterlogging tolerance in southern soybean germplasm. Crop Science, Madison, v. 43, n. 6, p. 2077-2082, 2003.

ROCHA, A. M. S.; MORAES, J. A. P. V. Influência do estresse hídrico sobre as trocas gasosas em plantas jovens envasadas de Stryphnodendron adstringens (Mart.) Coville. Revista Brasileira de Fisiologia Vegetal, Brasília, v. 9, n. 1, p. 43-48, 1997.

SCREMIN-DIAS, E.; LORENZ-LEMKE, A. P.; OLIVEIRA, A. K. M. The floristic heterogeneity of the Pantanal and the occurrence of species with different adaptive strategies to water stress. Brazilian Journal of Biology, São Carlos, v. 71, n. 1, p. 275-282, 2011.

SMIT, B.; STACHONIAK, M.; VAN VOLKENBURGH, E. Cellular processes limiting leaf growth in plants under hypoxic roots stress. Journal of Experimental Botany, Oxford, v. 40, n. 210, p. 89-94, 1989. SOARES, J. J.; OLIVEIRA, A. K. M. O paratudal do Pantanal de Miranda, Corumbá-MS, Brasil. Revista Árvore, Viçosa, v. 33, n. 2, p. 339-347, 2009.

TAIZ, L.; ZEIGER, E. Plant Physiology. 5th ed. Sunderland: Sinauer Associates, 2010. 690 p.

TOPA, M. A.; CHEESEMAN J. M. Effects of root hypoxia and low P supply on relative growth, carbon dioxide exchange rates and carbon partitioning in Pinus serotina seedlings. Physiologia Plantarum, Copenhagen, v. 86, n. 1, p. 136-144, 1992.

TOURNAIRE-ROUX, C. et al. Cytosolic $\mathrm{pH}$ regulates root water transport during anoxic stress through gating of aquaporins. Nature, London, v. 425, n. 6956, p. 393-397, 2003.

VOESENEK, L. A. C. J. et al. Plant hormones regulate fast shoot elongation under water: from genes to communities. Ecology, Washington, v. 85, n. 1, p. 16-27, 2004.

VU, J. V. C.; YELENOSKY, G. Photosynthetic responses of citrus trees to soil flooding. Physiologia Plantarum, Copenhagen, v. 81, n. 1, p. 89-94, 1991.

WALDHOFF, D.; FURCH, B. Leaf morphology and anatomy in eleven tree species from Central Amazonian floodplains (Brazil). Amazoniana, Kiel, v. 17, n. 1/2, p. 79-94, 2002. 